\title{
Spine surgery in the International Security Assistance Force Role 3 combat support hospital in Mazar-e-Sharif, northern Afghanistan, 2007-2014
}

\author{
Chris Schulz, MD, Uwe Max Mauer, PhD, Renè Mathieu, MD, and Gregor Freude, MD \\ Neurosurgical Clinic, German Federal Armed Forces Hospital Ulm, Germany
}

OBJECTIVE Since 2007, a continuous neurosurgery emergency service has been available in the International Security Assistance Force (ISAF) field hospital in Mazar-e-Sharif (MeS), Afghanistan. The object of this study was to assess the number and range of surgical procedures performed on the spine in the period from 2007 to 2014.

METHODS This is a retrospective analysis of the annual neurosurgical caseload statistics from July 2007 to October 2014 (92 months). The distribution of surgical urgency (emergency, delayed urgency, or elective), patient origin (ISAF, Afghan National Army, or civilian population), and underlying causes of diseases and injuries (penetrating injury, blunt injury/fracture, or degenerative disease) was analyzed. The range and pattern of diagnoses in the neurosurgical outpatient department from 2012 and 2013 were also evaluated.

RESULTS A total of 341 patients underwent neurosurgical operations in the period from July 2007 to October 2014. One hundred eighty-eight (55.1\%) of the 341 procedures were performed on the spine, and the majority of these surgeries were performed for degenerative diseases $(127 / 188 ; 67.6 \%)$. The proportion of spinal fractures and penetrating injuries $(61 / 188 ; 32.4 \%)$ increased over the study period. These spinal trauma diagnoses accounted for $80 \%$ of the cases in which patients had to undergo operations within 12 hours of presentation ( $n=70$ cases). Spinal surgeries were performed as an emergency in $19.8 \%$ of cases, whereas $17.3 \%$ of surgeries had delayed urgency and $62.9 \%$ were elective procedures. Of the 1026 outpatient consultations documented, $82 \%$ were related to spinal issues.

CONCLUSIONS Compared to the published numbers of cases from neurosurgery units in the rest of the ISAF area, the field hospital in MeS had a considerably lower number of operations. In addition, MeS had the highest rates of both elective neurosurgical operations and Afghan civilian patients. In comparison with the field hospital in MeS, none of the other ISAF field hospitals showed such a strong concentration of degenerative spinal conditions in their surgical spectrum. Nevertheless, the changing pattern of spine-related diagnoses and surgical therapies in the current conflict represents a challenge for future training and material planning in comparable missions.

https://thejns.org/doi/abs/10.3171/2018.9.FOCUS18389

KEYWORDS military neurosurgery; spine; spinal surgery; ISAF; Afghanistan; field hospital

S TARTING in 2006, a German Federal Armed Forces field hospital established in Mazar-e-Sharif, Afghanistan (MeS), has provided medical care for personnel of the International Security Assistance Force (ISAF) in northern Afghanistan. This multidisciplinary treatment unit was the only one of its kind in the north of the ISAF theater of operations, formerly known as "Regional Command North" (RC North). A maximum of 60,000 members of the Afghan National Army (ANA) and at times up to 30,000 ISAF soldiers, including some 5500 German soldiers, were stationed in this zone, an area of slightly more than $60,000 \mathrm{~km}^{2}$ with a civilian population of almost 7 million. The field hospital's main task was to provide acute medical care to the ISAF soldiers. At military medical care level 3 (or Role 3 according to the North Atlantic Treaty Organization [NATO] classification system) as applicable from 2006 to 2014, further diagnostic procedures and treatment for injured or sick soldiers are performed until the soldiers are stable enough for aeromedical evacuation to their home countries. In keeping with political and

ABBREVIATIONS ANA = Afghan National Army; ISAF = International Security Assistance Force; MeS = Mazar-e-Sharif; NATO = North Atlantic Treaty Organization; RC North $=$ Regional Command North.

SUBMITTED July 31, 2018. ACCEPTED September 12, 2018.

INCLUDE WHEN CITING DOI: 10.3171/2018.9.FOCUS18389. 
military guidelines, definitive treatment should be provided only if it results in the standard of treatment available in the patient's home country being achieved within an acceptable period of time (variably defined), after which the soldier can return to duty without restrictions (NATO Logistics Handbook. Chapter 16: Medical Support; http:// www.nato.int/docu/logi-en/1997/lo-1610.htm). For surgical fields, this meant that the field hospital was technically supplied with the diagnostic and treatment resources to avert acute dangers and to stabilize an acute situation until the injured or sick soldier could be transported by air. For logistical and other reasons, equipment and materials for advanced diagnostics or complex surgical procedures on the spine (e.g., MRI, surgical navigation, or more difficult spinal implants [except pedicle screw fixation]) were not kept available. In addition to treating the ISAF personnel, the field hospital also treated members of the ANA and, depending on the capacities available, Afghan civilian patients, for whom strategies for providing definitive treatment with the available resources had to be found even for complex injuries.

In the catchment area of RC North, there is no local civilian treatment unit capable of offering spine surgery at a higher level. As a result, patients from this region must seek and pay cash for treatment in Kabul, Pakistan, China, or India. However, most of the civilian population in question can hardly afford the great financial burdens of this type of treatment. This explains why ANA soldiers and civilian patients generally prefer treatment at the field hospital, which is highly qualified by local standards and certainly less expensive.

In conventional wars of the last century, spine surgery was not a major component of military surgery requirements. This has changed given the aspects of what are known as "asymmetric conflicts." In fact, spinal surgery has become one of the predominant areas of military surgery in the theater of conflict. ${ }^{13,15}$ Moreover, in past conflicts, field hospitals have primarily treated their own country's units. Now, however, the civilian population accounts for a significant number of patients in the German Federal Armed Forces military operations. The type and scope of diagnoses and specialized treatments completed at the ISAF field hospital in MeS, as well as the necessary consequences of this changed range, have not yet been reported. The spine-related operations performed in the MeS field hospital from July 2007 to October 2014 were analyzed to provide an overview of the range of indications for spinal operations and therefore the level of adjustments required for individual training. This analysis is also intended to serve as a source of information about the material and personnel requirements profile for future field hospital planning.

\section{Methods}

This is a retrospective analysis of the annual operation statistics from July 2007 to October 2014 (92 months). The cases were divided into groups according to surgical urgency, defined as emergency, delayed urgency, and elective indications. The emergency classification refers to procedures performed to avert an acute vital threat or to maintain acutely impaired central or peripheral neurological functions (e.g., spinal fracture with neurological impairment or lumbar disc herniation with acute cauda equina syndrome). Procedures with delayed urgency were intended to avert unfavorable developments in the condition or potentially severe complications and were performed within 12 hours of presentation as soon as logistical factors permitted (e.g., unstable spinal fracture without neurological impairment or spinal disc herniation with severe progressive paresis). Elective procedures were performed in the absence of a vital threat in order to treat chronic conditions for which conservative treatment was not sufficient (e.g., decompression for spinal stenosis). The distribution of patient origins (ISAF, ANA, civilian) and underlying causes of diseases and injuries (gunshot wound, fracture, degenerative disease) was also analyzed.

\section{Results}

\section{Population of Patients Operated on Between July 2007 and October 2014}

A total of 341 patients underwent neurosurgical operations in the period from July 2007 to October 2014. On the basis of 92 months of deployment, an average of 3.7 procedures was performed per month (Fig. 1). The lowest rate of operations occurred in the initial phase in 2007: 3 procedures from July to December, or 0.5 procedures per month (Fig. 2). Afterwards, the annual operation rate initially increased rapidly. The highest annual operation rate was in 2009: 76 procedures per year, or 6.3 procedures per month. After that, the annual figures for total neurosurgical operations decreased steadily. From January to the end of September in 2014, only 11 procedures were documented (1.2 procedures per month).

The main focus of operative neurosurgical treatment was the spine, with 188 procedures $(55.1 \%$ of the total number of neurosurgical procedures at an average of 2 procedures per month). The second most common procedure site was the head, with 122 procedures (35.8\% of the total number at an average of 1.3 procedures per month). Twenty-one procedures were performed on the peripheral nervous system $(6.2 \%$ of the procedures at an average of 0.2 procedures per month). The remaining procedures (e.g., soft tissue debridement) were summarized under "miscellaneous" (2.9\% of the total number at an average of 0.1 procedures per month).

\section{Distribution of Patient Origins and the Range and Severity of Indications for Spinal Operations}

Procedures for degenerative diseases accounted for the majority of neurosurgical spinal operations, particularly during the first half of deployment (Fig. 3). The percentage of spinal fractures and penetrating injuries increased during the study period and was approximately $50 \%$ during the second half of deployment. Spine surgeries were performed as an emergency in 19.8\% of cases, whereas 17.3\% of surgeries had delayed urgency and $62.9 \%$ were elective procedures. A total of 70 cases were defined as emergency or delayed urgency operative treatment; that is, treatment had to be provided within 12 hours of presentation in these cases. This restrictive timeframe meant that soldiers 


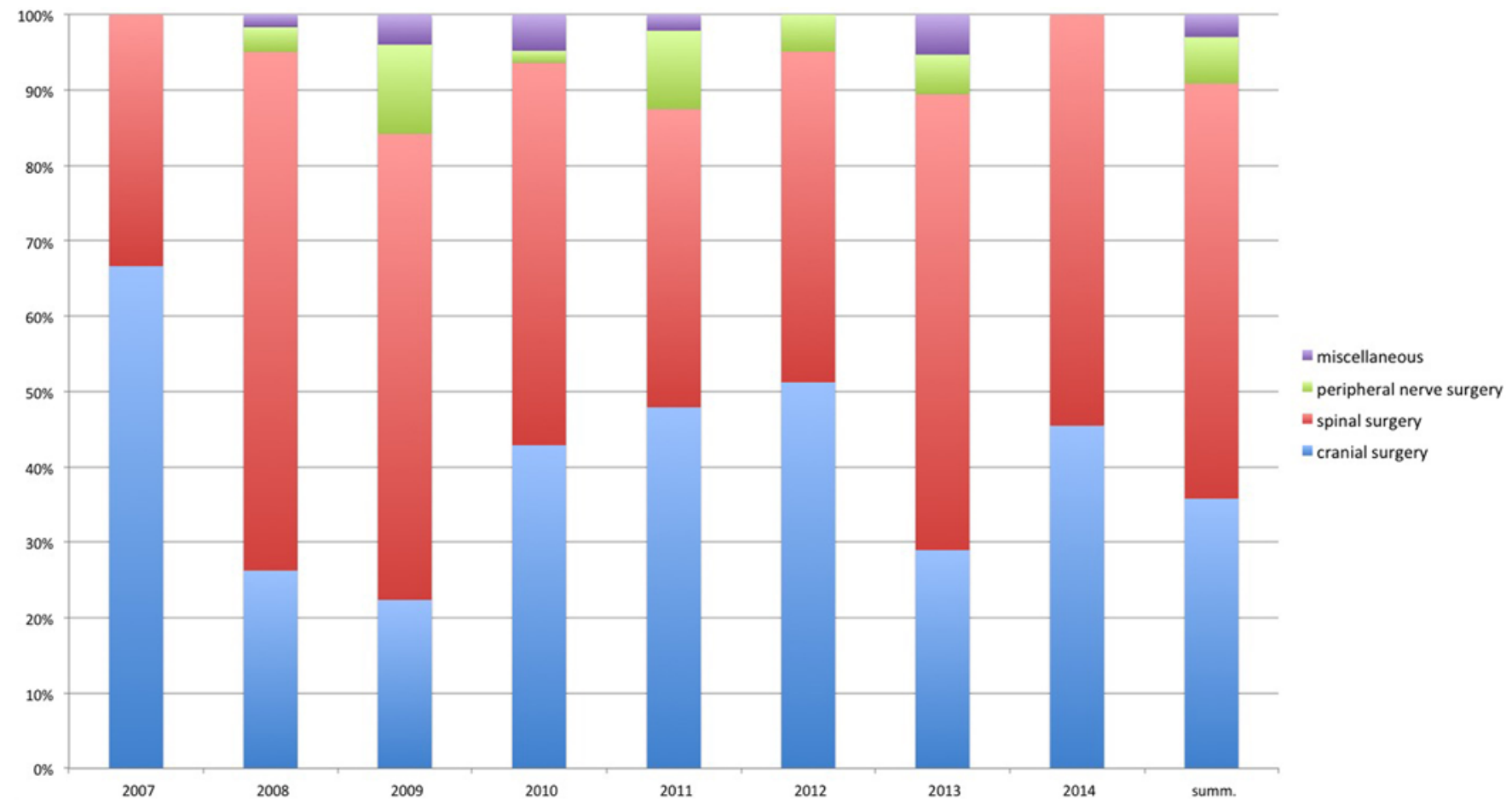

FIG. 1. Spectrum of neurosurgical procedures performed in 2007-2014. The y-axis represents the percentage of surgeries performed. summ. = summary.

from Germany's own forces and members of allied armed forces could not be considered for strategic aeromedical evacuation (StratAirMedEvac) and had to be treated on site. The same applied to Afghan civilians who could not be relocated for operative treatment of acute spinal conditions. Of the 37 cases in which emergency treatment was indicated, 8 were penetrating injuries ( 3 cervical, 2 thoracic, and 3 lumbar), 23 were fractures ( 6 cervical, 12 thoracic, and 5 lumbar), and 6 were degenerative diseases ( 2 acute cervical myelopathy and 4 severe lumbar disc herniation with cauda equina syndrome). Of the 33 cases with indications for operative treatment with delayed urgency, 7 were penetrating injuries ( 2 cervical, 1 thoracic, and 4 lumbar/sacral), 18 were fractures ( 8 cervical, 6 thoracic, and 4 lumbar), and 7 were degenerative diseases ( 2 cervical disc herniation, 1 thoracic spinal stenosis with acute myelopathy, and 4 lumbar disc herniation). Thirty-four of the 70 patients with indications for emergency or delayed urgency surgery had injuries whose causes were directly related to combat actions. Among these cases, closed fractures caused by blunt trauma (19 cases) outnumbered those caused by penetrating trauma (15 cases). Of the 41 emergency or urgent operations for spinal fractures, 3 were performed on children or adolescents (all with fractures at the thoracolumbar junction; ages 12-17 years). ISAF soldiers accounted for the smallest part of the spinal operative population at 18 cases $(9.6 \%$ of all spinal procedures at an average of 0.2 cases per month). During the observation period, 27 spinal operations were performed on members of the ANA (14.7\% of all spinal procedures at an average of 0.3 procedures per month). Additionally, spinal operations were performed on a total of 143 Afghan civilians $(76.1 \%$ of the spinal procedures at an average of 1.6 cases per month).

\section{Distribution of the Diagnostic Groups for Outpatient Consultations}

When this study was conducted, it was no longer possible to generate figures for outpatient services in the years before 2012. As a result, no longer-term developments in the number of patients or the range of outpatient care provided can be shown. However, it was still possible to reconstruct these figures for the field hospital in 2012 and 2013. Over the course of these 2 years, a total of 1026 outpatient consultations were performed (average of 1.4 patients per day). Analysis of the range of outpatient diagnoses showed that the clear majority of cases were spinal conditions (82\% of consultations; Fig. 4). Outpatient examinations were performed on 562 ISAF soldiers (54.8\%), 161 ANA members (15.7\%), and 303 Afghan civilians $(29.5 \%)$. Four hundred thirty-one $(42 \%)$ of the outpatient examinations were follow-up examinations of previous patients, most of whom were ISAF personnel (301/431; 69.8\%), followed by Afghan civilians $(102 / 431 ; 23.7 \%)$ and ANA personnel (29/431; 6.7\%).

\section{Discussion}

Compared to the published numbers of cases from Role 3 field hospitals in the rest of the ISAF area, the field hospital in MeS had a significantly lower number of operations. Furthermore, no other location had a range of opera- 


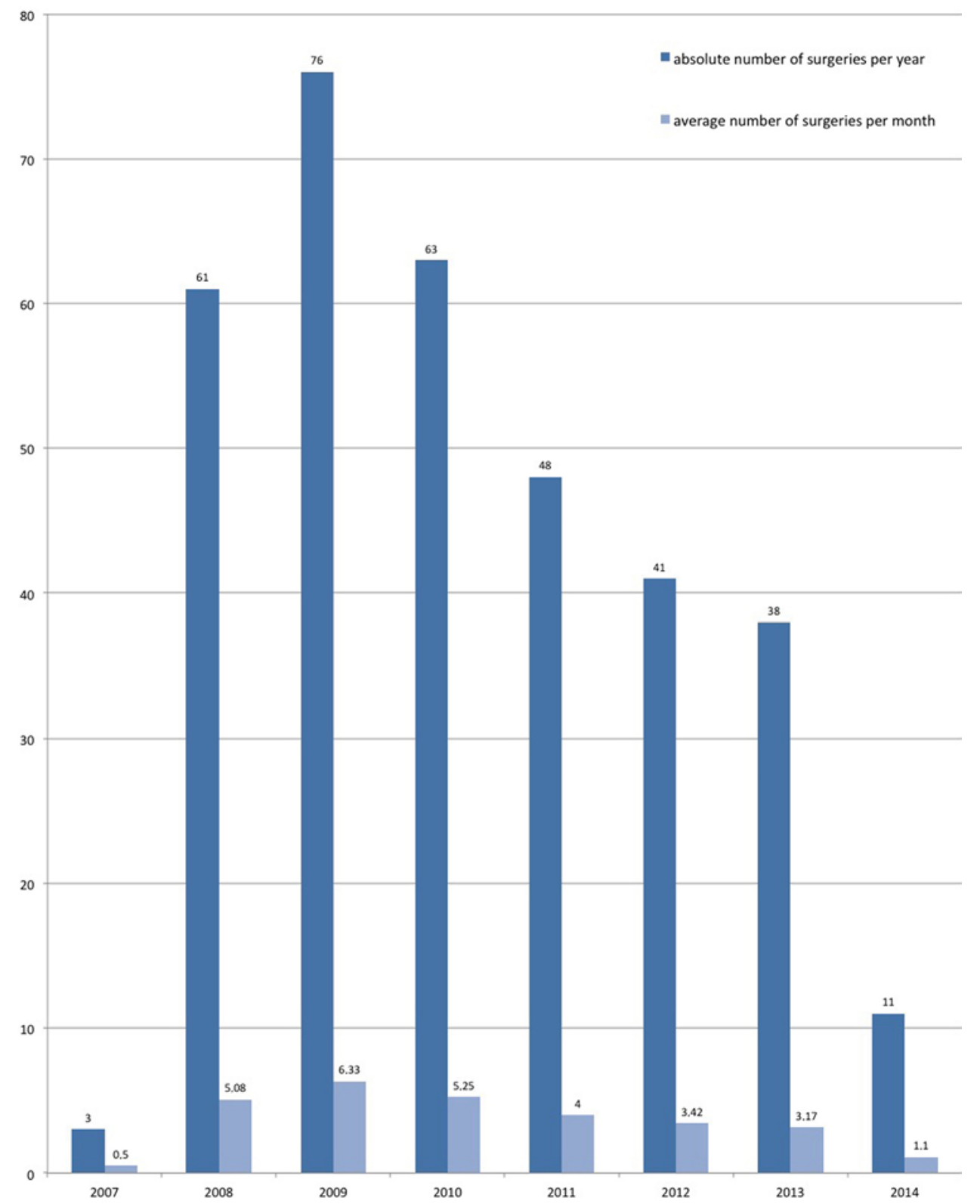

FIG. 2. Absolute annual and average monthly number of operations from July 2007 to October 2014. The y-axis represents the number of operations.

tions with as high a concentration of degenerative spinal conditions as MeS. In addition, the MeS unit had the highest rates of both elective neurosurgical operations and procedures performed on Afghan civilians..$^{2-4,7-10,15-17}$ These differences from the other ISAF Role 3 field hospitals in Kabul, Bagram, Kandahar, and Lashkargah were clearly attributable to the relatively small number of troops, the less extensive combat activity and external threat situation, and regional factors with regard to religious, cultural, and ethnic conditions in northern Afghanistan.

Fortunately, the number of spinal operations on ISAF soldiers was low: only 18 cases. This figure peaked between 2010 and 2012. The surgical procedures for members of the ANA almost tripled in the second half of the mission (a total of 27 cases, also peaking between 2010 and 2012). Procedures for ISAF and ANA personnel combined made up about $11 \%(14 / 122)$ of the cases in the first half of the mission. In contrast, the rate increased significantly to about $47 \%$ (31/66) during the second half of the mission. The disproportionate increase in this rate is attributable not only to the increased number of ISAF and ANA members undergoing operations (17 more cases), but also largely to the dramatic decrease in procedures on Afghan civilians ( 73 fewer cases). Afghan civilians accounted for almost $90 \%$ of spinal procedures during the first half of the mission but only slightly more than $50 \%$ during the second half. This decrease was due to external factors such as the significant increase in the number of 


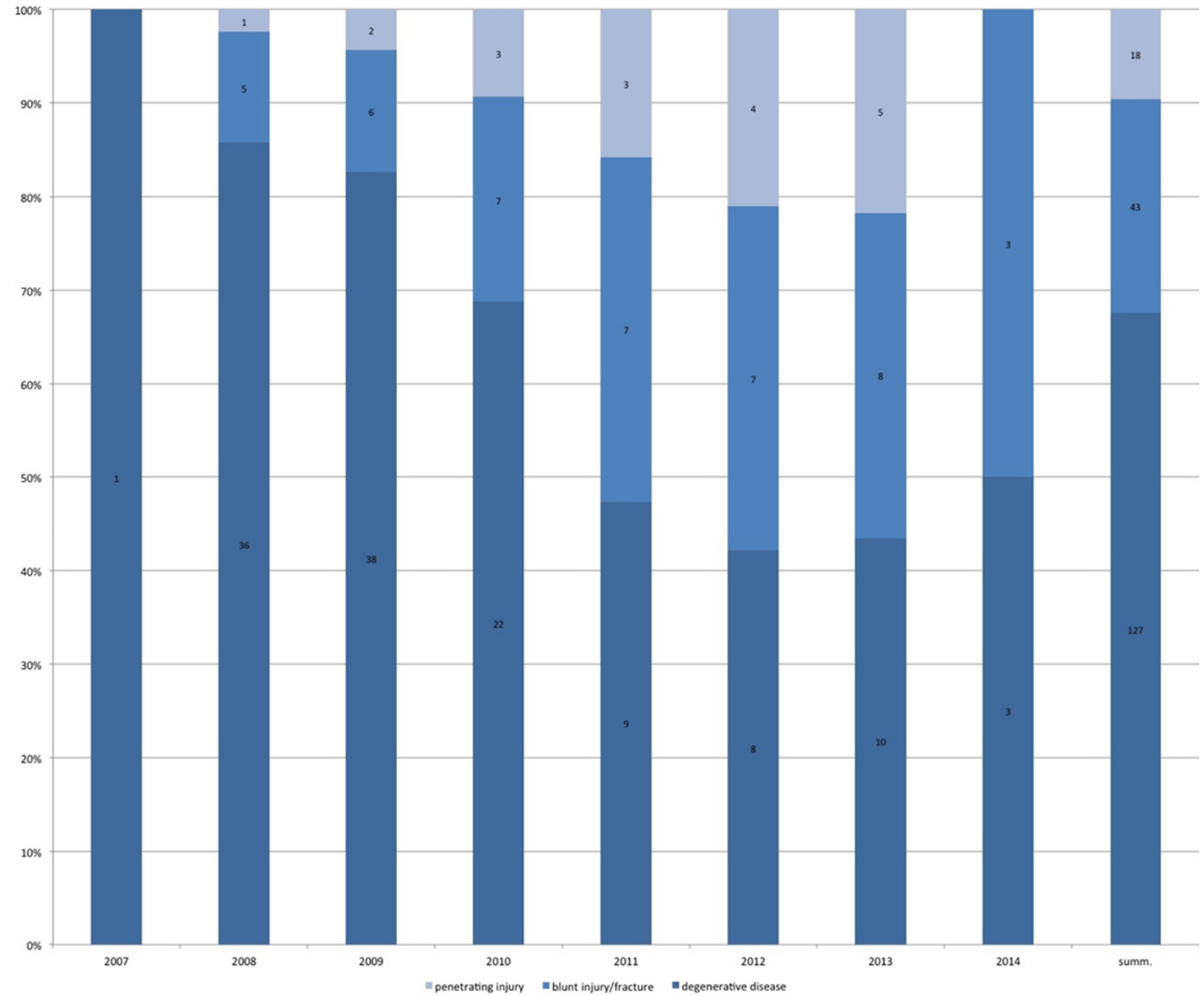

FIG. 3. Relative annual frequency of spinal operative diagnoses or procedures from July 2007 to October 2014.

troops and the external threat situation in northern Afghanistan (a change that was also detected in other ISAF combat hospitals). ${ }^{7}$ Starting in 2010, both of these factors resulted in an increased concentration of the field hospital's resources on its primary area of responsibility, that is, the provision of operative capabilities for members of the ISAF and ANA. Toward the end of the mission, a gradual "withdrawal strategy" was adopted with regard to the operative care of civilians in order to prevent medical care from being cut off abruptly when the ISAF mission ended in December 2014. This approach was also intended to shift the focus to treatment systems within the local civilian healthcare sector (for civilian patients) and to expand the range of services at the ANA hospital in MeS (for ANA soldiers and other local security forces).

If we assume that the cases required for "mission accomplishment" were exclusively spinal procedures on ISAF and ANA patients with progressive neurological conditions involving intraspinal masses (i.e., cases with an urgent indication or delayed urgency), we must conclude that under this guideline only $39(21 \% ; 17$ ISAF and 22 ANA cases at an average of 0.4 cases per month) of the 188 spinal operations were in line with the mission. If we round up, that would come out to about one procedure during each specialist's tour of duty, which generally lasts about 8 weeks. There would scarcely be any opportunity to build a team in the operating room or to provide proficiency training for spinal trauma emergencies. The German Armed Forces Surgery Consultancy Group classifies even an average caseload of $2-3$ cases per week (i.e., $8-12$ cases per month), as was observed in certain phases for the general/trauma surgery teams in Kunduz (a Role 2 unit in the northeast of Afghanistan), as too low for surgical operation teams that are not used to working with each other to attain a highly standardized level. ${ }^{6}$ Thus, a minimum number of elective operations and especially acute 


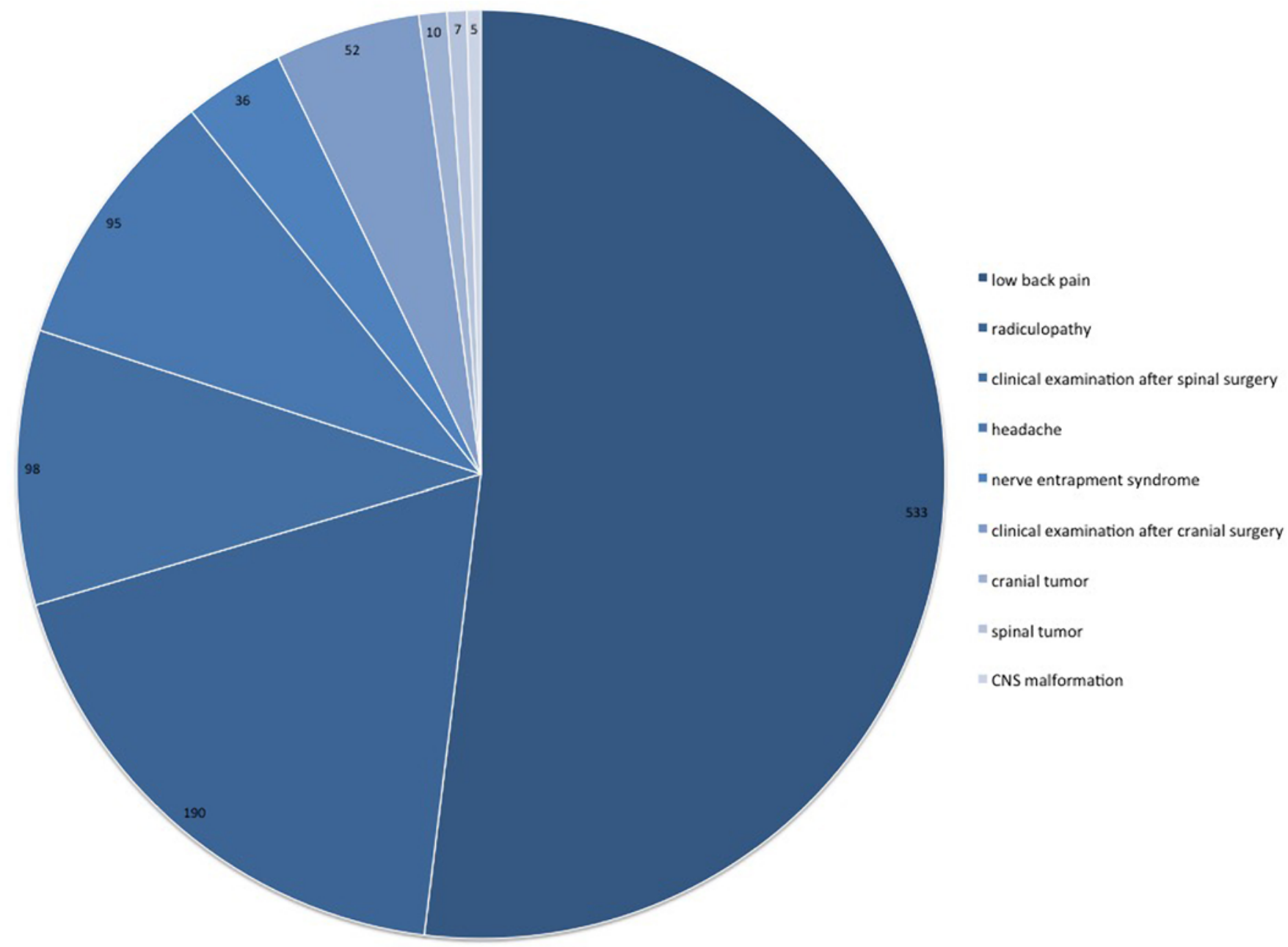

FIG. 4. Relative frequency of diagnoses in the neurosurgical outpatient department from January 2012 to December 2013.

operations, including those on civilian patients, are necessary to develop certain standards during the perioperative period on site, to identify organizational problems and possible defects in equipment or materials, and to ensure that such problems or defects have been eliminated-not to mention the ethical and moral aspects with regard to the unquestionably needy majority of the local population. While refusing to perform any procedures outside of acute situations for ISAF and ANA personnel saves resources for a possible mass casualty of soldiers, it also presents the risk of insufficient training and experience in the field hospitals on site.

One hundred forty-nine of the 188 procedures-which had to be included in order to raise the average to about one spinal operation per week-were performed either electively or on Afghan civilian patients, i.e., not in keeping with the guidelines in a strict military sense. However, the hospital was still able to provide specialized spinerelated surgical treatment to its actual target population (ISAF and ANA) at all times. It is to be assumed or hoped that this operative care outside of the mission's requirements had a positive effect on military processes within northern Afghanistan (e.g., proficiency training for surgi- cal teams, treating and/or not repatriating ISAF specialist personnel in theater, or enhancing positive reception of the mission among the Afghan civilian population) and thus paid off. These arguments could certainly justify the deviation from the actual mission.

The training guidelines for deployed German Federal Armed Forces general or orthopedic surgeons do not explicitly include the field of spinal operations. ${ }^{18,19}$ The interdisciplinary agreement between the German Federal Armed Forces trauma surgeons and neurosurgeons for the ISAF area of operations was originally that no specialized spine surgery would be performed on German troops in the country of deployment (with the exception of simple decompression procedures to treat acute narrowing of the spine, followed by rapid aeromedical evacuation back to Germany). The experiences of other authors also show that performing aggressive, early operations in theater can certainly have negative consequences, such as more frequent complications due to infections and more revision surgeries. ${ }^{5,14}$ However, the figures here show that the likelihood of complex spinal procedures becoming necessary (e.g., due to penetrating traumas) increases when there are a sufficient number of ISAF troops and a relevant increase 
in combat activity and the threat situation, which are often linked to each other. And, of course, if local security forces and the local population are to be included in a field hospital's treatment concept, we must expect a significant percentage of spine-related surgical cases of all urgency types and respond to it with sufficiently trained personnel and suitable materials. Spinal penetrating and blast injuries, for example, are rare in Germany. However, competence in these fields must be available in the mission areas.,11 In addition to acute spinal traumatology, the conditions of increasingly combined missions (i.e., ones with additional securing and supporting aspects) also require capabilities in the fields of degenerative diseases and pediatrics. As a result, the special training profile for modern military (neuro)surgeons after their civilian board certification must be adjusted to these changes in Germany as well. In addition to the more expected diagnoses of and treatments for acute trauma, there was also a significant demand for degenerative and even pediatric spine surgery (throughout the entire range of procedures and often as a definitive therapy). This expertise-including all intradural and extradural procedures for trauma and elective patients, as well as postinflammatory and posttraumatic deformities and instabilities from C0 to S1 with ventral and dorsal approaches-is not covered in its entirety or in a large number of cases either by the specialty training regulations for board certification of the individual surgical fields that focus on spinal conditions (trauma surgery, orthopedic surgery, neurosurgery) or by most home military hospitals/departments. However, individual mission-specific training must go beyond civilian board certification and daily routines to integrate these special aspects because this type of expertise was required both in practical and in technical/theoretical terms in MeS in past years. Basic training in at least the theoretical areas could be provided, for example, through the German Spine Society (DWG) module certifications or the (equivalent) EUROSPINE Diploma, which both present the basic diagnostic and treatment principles required. It also remains to be discussed whether it makes sense for military (neuro) surgeons to have practical training rotations in treatment units that cover the entire range of spinal procedures (e.g., in accordance with the national DWG institutional certification for level I centers in Germany [www.dwg.org/ zertifizierung/] or fellowships in endorsed host training centers of the EUROSPINE society [www.eurospine.org/ education.htm]; i.e., including intradural procedures and pediatric cases for all spinal segments and all approaches). In any case, however, it is necessary to ensure that all involved parties are sufficiently prepared to handle this new range of operations in terms of training the neurosurgery residents and keeping the proper hardware as well as surgical instruments available on site (CT, operating microscopes, microinstruments, surgical high-speed burr power systems, spinal implants for different types of fusions or vertebral body replacement, etc.) to avoid off-label applications of surgical instruments and implants for spinal procedures. ${ }^{12}$

\section{Conclusions}

In contrast to initial expectations, the spine was the main area of neurosurgical operative and outpatient activities in the ISAF field hospital in MeS. The absolute number of cases was considerably lower than that in the other ISAF field hospitals in eastern and southern Afghanistan; however, the rates for elective procedures, degenerative indications, and Afghan civilian patients were the highest. While the number of operations decreased considerably over the observed period of deployment from 2007 to 2014 and the range of operations shifted dramatically given external factors (toward more fractures and penetrating injuries), spinal indications consistently accounted for the largest percentage of neurosurgical procedures.

The standard equipment of German Federal Armed Forces mobile surgical hospitals (NATO Role 2, emergency general and trauma surgery capabilities) does not include CT, which largely eliminates the need for spine surgery expertise at this level. Facilities for Role 3 and higher are equipped with CT, and both a trauma surgeon and a neurosurgeon are available on site. At this level of care, if not before, "the whole spine" must be classified as a core competency of both fields (including surgical and conservative procedures). Pre-deployment training for trauma surgeons and neurosurgeons in this specialized field must be planned accordingly. It could be roughly based on national (https:// www.dwg.org/zertifizierung/persoenliche-zertifizierung/ module/) or international certification guidelines, for example, according to the EUROSPINE Diploma (www. eurospine.org/european-spine-course-diploma.htm\#). In the conflict theater, even regular non-mission-based neurosurgical procedures are valuable for maintaining the competency of operative teams as well as the surrounding infrastructure. Therefore, this humanitarian neurosurgery is clearly recommended in the setting of field hospitals, especially in units with a low operational tempo.

\section{References}

1. Blair JA, Possley DR, Petfield JL, Schoenfeld AJ, Lehman RA, Hsu JR: Military penetrating spine injuries compared with blunt. Spine J 12:762-768, 2012

2. Brisebois RJ, Tien HC: Surgical experience at the Canadianled Role 3 Multinational Medical Unit in Kandahar, Afghanistan. J Trauma 71 (5 Suppl 1):S397-S400, 2011

3. Dulou R, Dagain A, Delmas JM, Lambert E, Blondet E, Goasguen $\mathrm{O}$, et al: The French mobile neurosurgical unit. Neurosurg Focus 28(5):E13, 2010

4. Eisenburg MF, Christie M, Mathew P: Battlefield neurosurgical care in the current conflict in southern Afghanistan. Neurosurg Focus 28(5):E7, 2010

5. Formby PM, Wagner SC, Kang DG, Van Blarcum GS, Pisano AJ, Lehman RA Jr: Reoperation after in-theater combat spine surgery. Spine J 16:329-334, 2016

6. Güsgen C, Achatz G, Palm HG, Kollig E, Engelhardt M, Willy $\mathrm{C}$, et al: [Spectrum of surgical procedures performed in German rescue centers and the field hospital in Afghanistan in 2008.] Unfallchirurg 113:99-105, 2010 (Ger)

7. Jacobs N, Taylor DM, Parker PJ: Changes in surgical workload at the JF Med Gp Role 3 Hospital, Camp Bastion, Afghanistan, November 2008-November 2010. Injury 43:1037-1040, 2012

8. Joubert C, Dulou R, Delmas JM, Desse N, Fouet M, Dagain A: Military neurosurgery in operation: experience in the French role-3 medical treatment facility of Kabul. Acta Neurochir (Wien) 158:1453-1463, 2016

9. Peoples GE, Gerlinger T, Craig R, Burlingame B: Combat 
casualties in Afghanistan cared for by a single Forward Surgical Team during the initial phases of Operation Enduring Freedom. Mil Med 170:462-468, 2005

10. Ragel BT, Klimo P Jr, Kowalski RJ, McCafferty RR, Liu JM, Taggard DA, et al: Neurosurgery in Afghanistan during "Operation Enduring Freedom": a 24-month experience. Neurosurg Focus 28(5):E8, 2010

11. Ramasamy A, Hinsley DE, Edwards DS, Stewart MP, Midwinter M, Parker PJ: Skill sets and competencies for the modern military surgeon: lessons from UK military operations in Southern Afghanistan. Injury 41:453-459, 2010

12. Ravindra VM, Wallace SA, Vaidya R, Fox WC, Klugh AR III, Puskas D, et al: Spinal stabilization using orthopedic extremity instrumentation sets during Operation Enduring Freedom-Afghanistan. World Neurosurg 86:503-509, 2016

13. Schoenfeld AJ, Laughlin MD, McCriskin BJ, Bader JO, Waterman BR, Belmont PJ Jr: Spinal injuries in United States military personnel deployed to Iraq and Afghanistan: an epidemiological investigation involving 7877 combat casualties from 2005 to 2009. Spine (Phila Pa 1976) 38:1770-1778, 2013

14. Schoenfeld AJ, Mok JM, Cameron B, Jackson KL, Serrano JA, Freedman BA: Evaluation of immediate postoperative complications and outcomes among military personnel treated for spinal trauma in Afghanistan: a cohort-control study of 50 cases. J Spinal Disord Tech 27:376-381, 2014

15. Schulz C, Kunz U, Mauer UM: Three years of neurosurgical experience in a multinational field hospital in northern Afghanistan. Acta Neurochir (Wien) 154:135-140, 2012

16. Shah K, Pirie S, Compton L, McAlister V, Church B, Kao $\mathrm{R}$ : Utilization profile of the trauma intensive care unit at the Role 3 Multinational Medical Unit at Kandahar Airfield between May 1 and Oct. 15, 2009. Can J Surg 54:S130-S134, 2011

17. Turner CA, Stockinger ZT, Bell RS, Gurney JM: Neurosurgical workload during US combat operations: 2002 to 2016. J Trauma Acute Care Surg 85:140-147, 2018
18. Willy C, Gutcke A, Klein B, Rauhut F, Friemert B, Kollig EW, et al: [The educational program for modern military surgeons.] Unfallchirurg 113:114-121, 2010 (Ger)

19. Willy C, Hauer T, Huschitt N, Palm HG: "Einsatzchirurgie"-experiences of German military surgeons in Afghanistan. Langenbecks Arch Surg 396:507-522, 2011

\section{Disclosures}

The authors report no conflict of interest concerning the materials or methods used in this study or the findings specified in this paper.

\section{Author Contributions}

Conception and design: Schulz. Acquisition of data: Freude. Analysis and interpretation of data: Schulz. Drafting the article: Mathieu. Critically revising the article: Mauer. Approved the final version of the manuscript on behalf of all authors: Schulz. Administrative/technical/material support: Mathieu. Study supervision: Mauer.

\section{Supplemental Information Previous Presentations}

Portions of this work were presented in oral presentation form at the 15th Interim Meeting of the WFNS held in Rome, Italy, on September 10, 2015.

\section{Correspondence}

Chris Schulz: German Federal Armed Forces Hospital Ulm, Germany. chris.schulz@uni-ulm.de. 